Although the above reductions of a series of selfcontained observations on atmospheric extinction yield a determination of $n_{0}$ to an order of accuracy not very much less than that of the best existing determinations, their chief interest lies in the fact that they constitute as rigorous an experimental test of Rayleigh's law as may be expected in view of the practical impossibility of securing absolutely perfect atmospheric conditions. From the value of $\gamma$ may be calculated the fraction of radiant energy converted per $\mathrm{cm}$. of path into thermal molecular agitation; taking a value of $\gamma_{0}=0.032$ for air under standard conditions, it is easily shown that in a stream of radiation corresponding to the solar constant the rate of increase of temperature amounts to $0.015^{\circ} \mathrm{C}$. an hour. ${ }^{14}$ As the above value of $\gamma$, even for the comparatively dust-free air above Mount Wilson, includes to a certain extent the effect of volcanic haze, it follows that in a pure gas partition of energy cannot take place at a rate greater than is represented by the above-mentioned rate of increase of temperature. We have in this case an excellent illustration of two interpenetrating dynamical systems (the æthereal system of electromagnetic waves and the molecular gaseous system) allowing of partition of energy, it at all, at an excessively slow rate compared with the rate of equalisation of energy distributions which is capable of being realised in each system considered separately. It is interesting to notice also that this rate is enormously increased by the presence of constrained molecular systems (matter in the solid or liquid state, such as dust-particles, water droplets, etc.).

Further, the experimental verification of Rayleigh's law to a high degree of accuracy is interesting in that its final expression is a result of classical dynamics and continuous absorption and re-emission of energy; from this point of view it seems to the writer that the hypothesis of emission by "quanta" cannot be universally applied to radiating molecular systems.

In this connection it is interesting to notice that in the recent theory of specific heats as proposed by Debye, ${ }^{15}$ Born and Kàrmàn, ${ }^{16}$ and now generally recognised as an adequate interpretation of experimental results, the interpretation of Planck's constant $h$ has been transferred from association with the individual atom to the process whereby energy is interchanged between molecular systems vibrating under those intramolecular forces and constraints which in their integrated form determine the elastic properties of the solid state. Similarly in view of the abovementioned verification of Rayleigh's law it is difficult to see how Planck's "quantum" can be associated with the individual molecule, at any rate for that system of vibrations which enter into the forced oscillations with consequent re-emission of radiant energy thus constituting the phenomenon of molecular scattering. In the opinion of the writer one might with advantage seek for the interpretation of Planck's $h$ in the problem of "black-body" radiation in the fact that the radiating units probably perform vibrations under the intramolecular forces and constraints which determine the solid state, while at the same time the reaction of the total aggregate of radiating systems must profoundly modify the character of the radiation from the original sources before it emerges from the interior of the solid into free space for experimental examination.

Louis V. KING.

McGill University, June 6, I9I4.

14 King, loc. cit., p. 394

15 Debye, Ann, der Phys., iv , 39, p. 789 . (ror2.)

26 Born and Kàrmàn, Phys. Zeitschr., xiv., p. 15; also p. 65. (I9r3.) NO. 2335, VOL. 93]

\section{The Destruction of Wild Peafowl in India.}

MAY I direct attention to the subjoined extract from the Englishman of Calcutta of June 4 last? It will give some idea of the degree to which wild peafowl are being destroyed in India so long as the open market for foreign plumage exists in the maritime countries of Europe. Of course, there is no objection whatever to the use of peacocks' feathers in any form of art, but sufficient for the purpose should be obtained from the millions of domesticated peafowl in Europe, Asia, America, and North Africa, without pursuing a war of extermination against the wild species still remaining in India. The peacock sheds his wondrously beautiful tail feathers every summer or early autumn, but I have reason to think that the bulk of the peacocks' plumes exported from India are derived from wild birds shot for the purpose. $\mathrm{Mr}$. C. William Beebe, of the New York Zoological Society, has already directed attention to the extent to which the peafowl of India and Burma are being eliminated from the woodland. One would only ask in this case control of the destruction within reasonable limits.

H. H. Johnston.

"On Tuesday, the Calcutta Customs authorities seized forty-four large cases containing peacock feathers on one of the steamers. These cases were to be delivered at Hamburg. By a mere chance, they escaped detection when first presented before shipment at the Customs office, but when they had been placed on board the steamer, information reached the Customs authorities as to their contents. Promptly, Customs officers were sent to bring back the cases to the office, where on examination they were found to contain peacock feathers.

"The feathers will of course be confiscated and the exporter, whose name was not disclosed, will, if found, be fined heavily. This consignment of feathers, in a way, constitutes a record. A feather which costs half an anna in India brings in a very considerable sum in Germany.

"It is stated that cases of smuggling feathers are now again becoming very common, and the Customs officers are almost daily making seizures of the contraband article. In spite, however, of their vigilance in some cases, the smugglers succeed in sending away feathers. The smugglers employ ingenious methods; in many instances they send the feathers under assumed names; then the consignee's name is also very difficult to ascertain and in some cases, where valuable feathers are concerned, the smugglers send them by post in letters or as registered parcels.

"There is at the present moment a large demand for peacock feathers in Europe, and the majority of the consignments detected in Calcutta contained feathers."-The Englishman, June 4, I9I4.

\section{THE AUSTRALIAN MEETING OF THE BRITISH ASSOCIATION.}

MORE than three hundred members of the Mritish Association (including some forty foreign and colonial members) are on their way to Australia to attend the eighty-fourth annual meeting, which begins in Adelaide on August 8. The Australian organisation has found it possible to offer hospitality to the whole party without distinction, and the State Governments are providing all the visitors with passes over their respective railway lines during the time of the official meeting. A number of leading members have already been for some time in the country for purposes of 
research, and others will remain for some weeks or months after the proceedings terminate in Brisbane on September I. In the desire that the visitors should spend their few week-ends in acquainting themselves with extra-metropolitan activities and possibilities, a heavy programme of tours has been arranged, and upon these all members from overseas will be the guests either of the particular central State organisation concerned or of a committee in the locality visited. It is unfortunate from many points of view that it has been necessary to hold the meeting in one of the Australian winter months, for much of the pleasure of the excursions will depend upon the chances of the weather.

The Western Australian advance party of seventy began work in Perth on July 28 . In a previous article a summary was given of the places to be visited by the various divisions of the party. Public lectures will be delivered by Profs. W. A. Herdman (Liverpool) and A. S. Eddington (Cambridge), Dr. A. D. Waller (London), Mr. Henry Balfour (Oxford), and Mr. C. A. Buckmaster (London).

On August 8 the whole party from overseas will assemble in Adelaide. Twenty mineralogists and chemists will leave at once for Port Pirie and Broken Hill, the most famous smelting and mining centres in Australia. As guests of the manager of the Broken Hill Proprietary Company and of the Broken Hill Mining Managers' Association they will spend four very strenuous days before rejoining their colleagues in Adelaide. At the first evening discourse to be delivered by the retiring president, Sir Oliver Lodge, the chair will be taken by the Governor of South Australia (vice-president), who will officially welcome the Association to the State. Sir Oliver Lodge has taken as his subject "The Æther of Space." The second discourse will be by Prof. W. J. Sollas (Oxford), while Prof. E. C. K. Gonner (Liverpool) will deliver a Citizens' Lecture. Sectional presidential addresses will be given in geography and agriculture. The social engagements of the stay in Adelaide include a reception by the Governor and $\mathrm{a}$ ball by the mayor.

The sectional work proper begins in Melbourne, where the party will arrive in three special trains

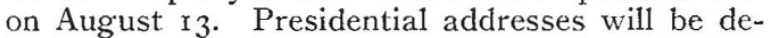
livered in the sections of physics and mathematics, chemistry, zoology, economics, and physiology. Both here and in Sydney the sectional sessions will be devoted largely to discussions upon broad problems. Among the subjects to be brought forward are the structure of atoms and molecules, metabolism, the nature and origin of species, wireless telegraphy, the physiography of arid lands, some antarctic problems, mimicry in Australian insects, town planning, is Australian culture simple or complex?, the study of native culture in relation to administration, climate from the physiological point of view, anæsthetics, the origin of the angiosperms, the literary side of education, vocational education, irrigation and dry farming. Town planning will be a leading feature of the work of the economics section, and the plans for the new federal capital have been lent to the section by the Commonwealth Government. To those economists whose interests lie in current practical politics, the fact that Australia will, throughout the meeting, be preparing for a General Election early in September may offer some attraction.

Melbourne being the temporary seat of Government, its social functions include a reception by the Governor-General and the Federal Ministry, to be held on the first night of the meeting. In addition, the State Governor and Government and the Lord Mayor will entertain the Association. Prof. Bateson will deliver the first part of his presidential address, and discourses will be given by Prof. E. B. Poulton (Oxford) and the Astronomer Royal, and Citizens' Lectures by Prof. H. B. Dixon (Manchester) and Dr. WV. Rosenhain (National Physical Laboratory).

The long journey of 600 miles to Sydney will be made during the night of August I9, and on the evening of the following day will be delivered the second part of the presidential address. The public lecturers in Sydney are Sir Ernest Rutherford, Prof. Elliot Smith (Manchester), Prof. Benjamin Moore (Liverpool), and Prof. H. H. Turner (Oxford). In the sections, besides discussions and papers there will be presidential addresses in geology, engineering, anthropology, botany, and education. The lighter side of the programme includes a luncheon by the State Government and entertainments by the State Governor and the Senate of the University, and a ball by the Lord Mayor.

After the Sydney session the overseas party divides. Some seventy proceed to New Zealand, while some 200 travel further north on a twentyeight hours' journey to Brisbane. Here Mr. A. D. Hall (agriculture) and Prof. E. W. Brown, of Yale (cosmical physics), will address their sections, and public lectures will be given by Profs. H. E. Armstrong and G. W. O. Howe (London), Dr. A. C. Haddon (Cambridge), and at the last meeting, Sir Edward Schäfer. Social entertainments have also been arranged. It is likely that in most of the capital cities the universities will confer degrees honoris causa upon a few of the leading members of the visiting party.

It is not possible adequately and briefly to summarise the excursions programme. The organisation has endeavoured to include those localities most suitable from the point of view of the professional interests of the guests, at the same time not failing to include some places of chiefly scenic attraction. The limits imposed by the necessity for easy accessibility and by the exceedingly short time at disposal in any one State, have made the task very difficult. A wide and probably rather embarrassing choice will be open to the visitor, but except for those members who can remain in Australia after the meeting it will seldom be possible to journey very far from the coastline. The names of most of the places to which excursions have been planned have already been mentioned in a previous article.

Literature in abundance has been prepared for NO. 2335 , VOL. 93 
the use of members. The Federal Handbook gives general accounts of the scientifically important aspects of the country, and it was some time ago placed in the hands of prospective visitors. It is the intention of the Commonwealth Government also to present a copy to each member of the general committee and to each foreign corresponding member. An admirable supplement to this work is given by the handbooks issued by the respective States, and by booklets which deal specifically with the localities chosen as objects of excursions.

It is a misfortune that so great a proportion of the time which members can spare from their work in Great Britain must be spent on the ocean; but it may be conceded that the proposed arrangements in Australia, if successfully carried through, will have offered to the visiting party as full and well-chosen an opportunity for achieving the objects of a colonial meeting of the British Association as it is possible to obtain in the short space of three and a half weeks, devoted to visiting four cities distributed along a stretch of railway line $\mathrm{r} 800$ miles in length.

\section{THE ELECTRIC EMISSIVITY AND THE DIRECTIVE DISINTEGRATION OF HOT BODIES.}

[HAT department of physics which concerns 1 itself with the electrical and kindred properties of incandescent bodies has recently attracted a good deal of controversial attention. From the outset, the subject aroused great interest, possibly in view of its speculative possibilities for solar physicists and others, and numerous workers have carried its development into great detail and some complexity. In a short resumé of the two phenomena specifically mentioned in the title of this article, we can do no more than touch on general outlines. Of the several aspects, the electrical one, now generally known as "thermionics," calls for first mention.

Electric Emissivity.-It was Guthrie in 1873 , at the Royal School of Mines, who did pioneer work on what we now know to be a characteristic feature of incandescent bodies, and that is, to put it simply, their property of emitting an excess of positive electricity at a red heat, and at higher temperatures, a much larger excess of negative. The positive electrification, we have reason to believe, is carried chiefly by atoms or molecules of either occluded gas (such as CO), or impurities such as the alkali metals.

The degree of the negative emissivity at high temperatures was shown by subsequent workers, Elster and Geitel among others, to depend not only on the body and its temperature, but also on the nature and pressure of the surrounding gas. Sir J. J. Thomson established the fact that no matter what the nature of the hot body, the electron was the prime agent in the transport of the negative electricity; and later, Prof. O. W. Richardson (then a student at the Cavendish Laboratory), in his early work on a subject now associated with his name, concluded that these thermionic currents were due to a kind of "electric evaporation" of the unattached electrons ir: the solid.

Treating the problem from this point of view, Richardson derived his well-known expression :-

$$
I=a \theta^{2} C^{-l, j},
$$

where $I$ is the saturation current, $\theta$ the absolute temperature, and $a$ and $b$ are constants for any particular material. As will be seen, the formula (which is identical in type with that of Kirchoff for vapour-pressure, and shares its peculiar "elasticity") contemplates the electric emission as due solely to the effect of temperature.

It was not until rgi 2 that doubts were first cast on the adequacy of this explanation. Pring and Parker (Phil. Mag., January, I912), working in Sir Ernest Rutherford's laboratory at Manchester, took especial pains to purify and free from gas a sample of carbon rod, and in consequence of these precautions found that the thermionic emission from the rod in a high vacuum was reduced to a value of the order of a million times smaller than was indicated by Richardson's formula. Later, Pring (Proc. Roy. Soc., November, I9r3) continued and refined these experiments, and succeeded in further reducing the ionisation currents.

Clearly, Richardson's constants for carbon needed amending, as he himself readily recog. nised, though the two investigators still find themselves in disagreement (Richardson, Proc. Roy. Soc., May, 1914) as to the extent of the correction which is afforded by Pring's experiments.

This point remains at issue, but the further observations of Pring on the effect of introducing traces of different gases into the vessel containing the carbon strongly favour his contention that the thermionic currents owe their origin, at any rate in great part, to an interaction, probably of a cyclic character, between the carbon and the surrounding gas. Pring tried a number of gases -helium, argon, nitrogen, carbon dioxide, etc.and found that the ionisation effects at very low pressures followed closely the order of the known chemical activities. It may be noted that Fredenhagen, working about this time on sodium and potassium in a high vacuum, also concluded that the thermionic effect was a chemical one.

In the meantime, Harker and Kaye (Proc. Roy. Soc., February, I9I2), at the National Physical Laboratory, had approached the question from quite another point of view. With the object of accentuating these high-temperature currents, they had recourse to the carbon-tube resistance furnace. Under these conditions they obtained electrical emissions of unparalleled magnitude from carbon at atmospheric pressure, no electromotive force being applied. At temperatures approaching $3000^{\circ} \mathrm{C}$. the thermionic current attained a value of several amperes, and readily lit up a nest of small glow-lamps; it was no longer a question for electrometer or sensitive galvanometer. These investigators concluded that the effect in their experiments was largely conditioned by the furnace-gas and the expulsion of the impurities present in the carbon. In more recent work,

NO. 2335, VOL. 93] 